Acknowledgment. This research was supported by the U.S. Department of Energy under Contract EY-76-S-02-3416. Thanks are also due to the Education Committee of the Gulf Oil Corp. for a grant that assisted in the construction of the apparatus.

\section{References and Notes}

(1) U.S. Department of Energy Document No. EY-76-S-02-3416-11

(2) G. W. Goodloe, E. R. Austin, and F. W. Lampe, J. Am. Chem. Soc., 101, $3472(1979)$.

(3) G. W. Goodloe and F. W. Lampe, J. Am. Chem. Soc., 101, 5649 (1979)

(4) D. H. O'Brien and T. J. Hairston, Organomet. Chem. Rev., Sect. A, 7, 95 (1971).

(5) R. J. P. Corrier and M. Henner, J. Organomet. Chem., 74, 1 (1974).

(6) M. Menzinger and L. Wăhlin, Rev. Sci. Instrum., 40, 102 (1969).
(7) W. Wien, Ann. Phys. (Leipzig), 65, 440 (1898).

(8) L. Wahlin, Nucl. Instrum. Methods, 38, 133 (1965)

(9) M. Menzinger and R. Wolfgang, J. Chem. Phys., 50, 2991 (1969)

(10) G. W. Stewart, J. M. S. Henis, and P. P. Gaspar, J. Chem. Phys., 57, 1990 (1972).

(11) T. M. H. Cheng, T. Y. Yu, and F. W. Lampe, J. Phys. Chem., 77, 2587 (1973).

(12) F. P. Lossing and G. P. Semeluk, Can. J. Chem., 48, 955 (1970)

(13) P. Potzinger, A. Ritter, and J. R. Krause, $Z$. Naturforsch. A, 30, 347 (1975).

(14) J. L. Franklin, J. G. Dillard, H. M. Rosenstock, J. T. Herron, K. Draxl, and F. H. Field, Natl. Stand. Ref. Data Ser., Natl. Bur. Stand., No. 26 (1969).

(15) E. W. McDaniel, V. Cermak, A. Dalgarno, E. E. Ferguson, and L. Friedman "Ion-Molecule Reactions", Wiley-Interscience, New York, 1970, p 13 ff.

(16) M. K. Murphy and J. L. Beauchamp, J. Am. Chem. Soc., 98, 1433 (1976).

(17) D. M. Shold and P. Ausloos, J. Am. Chem. Soc., 100, 7915 (1978).

\title{
Methyl-Substituted Allyl Cations. A Comparison of Experimental Stability, Rotational Barrier, and Solvolysis Data with ab Initio Calculations
}

\author{
Herbert Mayr,* Wolfgang Förner, and Paul von Ragué Schleyer \\ Contribution from the Institut für Organische Chemie der Universität \\ Erlangen-Nürnberg, 8520 Erlangen, West Germany. Received December 27, 1978
}

\begin{abstract}
Three sources of quantitative data for methyl-substituted allyl cations are available experimentally: Gas phase heats of formation, rotational barriers in solution, and rates of solvolysis. NMR chemical shifts also provide an index of charge distribution. This paper draws all these lines together in comparison with results of STO-3G ab initio molecular orbital calculations performed on planar and perpendicular methyl-substituted allyl cations. Sequential substitution of the terminal positions by one, two, three, and four methyl groups stabilizes allyl cations electronically by $17,15,13$, and $11 \mathrm{kcal} / \mathrm{mol}$, respectively; a methyl group on the central carbon has a much smaller stabilizing effect $(\sim 5 \mathrm{kcal} / \mathrm{mol})$. The steric strain for the first endomethyl group was determined to be $3 \mathrm{kcal} / \mathrm{mol}$, whereas a second endo-methyl experiences a somewhat greater strain of 5 $\mathrm{kcal} / \mathrm{mol}$. Allyl solvolysis rates correlate well with gas phase allyl cation stability data, but there is a reduction in magnitude due to solvation. The calculated rotational barriers also are $4-12 \mathrm{kcal} / \mathrm{mol}$ higher than the activation free enthalpies determined in superacid solution; the difference provides further evidence for differential solvation effects-the more highly delocalized planar forms are solvated to a lesser extent than their rotational transition states. The rotational barrier of the parent allyl cation is predicted to be $34 \mathrm{kcal} / \mathrm{mol}$ in the gas phase but to decrease to $23.7 \pm 2 \mathrm{kcal} / \mathrm{mol}$ in superacid solution.
\end{abstract}

Allyl cations, the prototype $\pi$ delocalized carbenium ions, have been studied experimentally for many decades. ${ }^{1}$ The solvolysis studies, which first proved the existence of allyl cations as short-lived reactive intermediates, preceded generation and direct observation of stable allyl cations in superacid media.' In recent years, many thermodynamic data on allyl cations in the gas phase have become available, particularly by means of ion cyclotron resonance measurements. ${ }^{2}$

Previous theoretical studies have concentrated on the parent allyl cation. ${ }^{3-8}$ With few exceptions, ${ }^{9 a}$ methyl-substituted allyl cations have only been investigated by semiempirical methods ${ }^{10.11}$ or by ab initio calculations without geometry optimization. ${ }^{12}$ Since these calculations give considerable deviations with experimentally determined energy differences, we undertook a comprehensive ab initio MO study of methyl-substituted allyl cations with geometry optimization in order to assess and to augment the experimental data.

\section{Methods}

All ab initio MO calculations on planar and perpendicular allyl cations were performed by utilizing the STO-3G minimal basis set ${ }^{13}$ and the Gaussian 70 series of programs. ${ }^{14}$ For the planar allyl cations, the heavy atom framework was fully optimized, until the total energy was constant to better than $10^{-5} \mathrm{au}$, bond lengths to $0.001 \AA$, and angles to 0.1 degrees; standard bond lengths and angles were used for the $\mathrm{CH}$ bonds (Table $\mathrm{I}$ ). The energy values thus obtained were only slightly higher than those of completely optimized structures, e.g., 1 $(\Delta E=0.5 \mathrm{kcal} / \mathrm{mol}), 4(\Delta E=0.7 \mathrm{kcal} / \mathrm{mol})$, and $6(\Delta E=1.0$ $\mathrm{kcal} / \mathrm{mol}) .^{15}$ The fully optimized structures are included in Table i.

The geometries of the perpendicular allyl cations were based on the completely optimized structure of the parent system. ${ }^{7}$ This geometry proved to be satisfactory also for substituted cations, since complete optimization of perpendicular 5 and 8 (rotation of $\mathrm{CH}_{2}$ group) resulted in energies only 0.5 and $1.8 \mathrm{kcal} / \mathrm{mol}$, respectively, below those given in Table IV.

Since the errors introduced by our less than complete optimization appear to be small and more or less constant, they tend to cancel in many of the energy comparisons. In section $A 2$, it will be shown that the relative energies of allyl cations, thus calculated, coincide with experimental gas phase data, which justifies the approximations employed.

\section{Results and Discussion}

A. Planar Allyl Cations. 1. Geometry. Heavy-Atom Framework. The results of STO-3G calculations on the planar allyl cations are summarized in Table I. All allyl cations were assumed to have planar heavy-atom ground states. This was justified on the basis of the planar preference of a member of the set more prone to twisting: An energy increase was calculated when the 3,3-dimethylallyl cation (8), which has a relatively low rotational barrier (see below), was twisted by only $15^{\circ}$ around the C-2-C-3 bond. In contrast, INDO predicted 


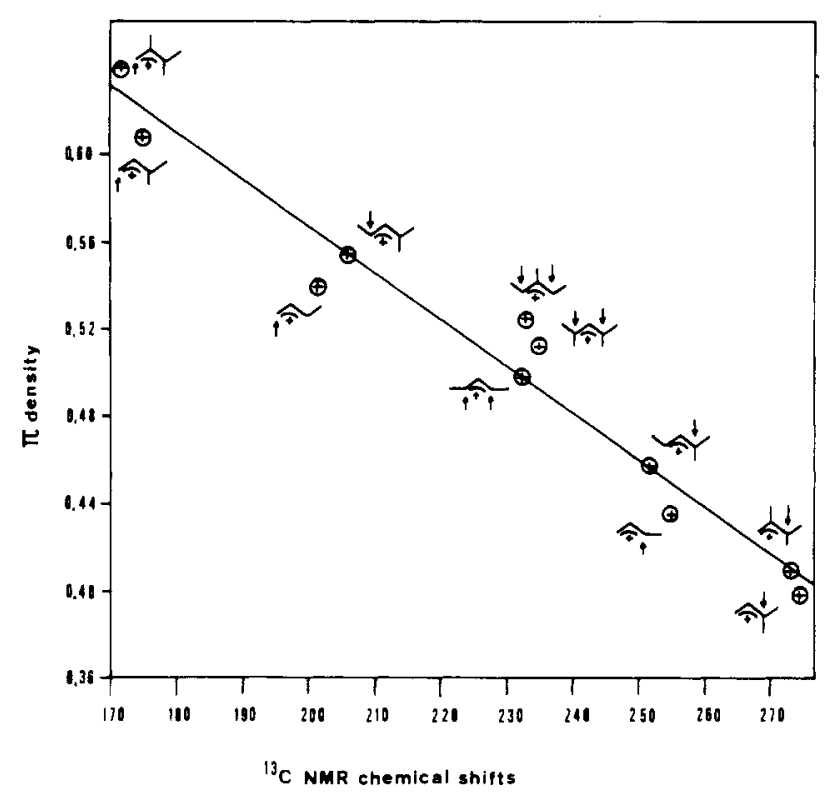

Figure 1. Correlation between ${ }^{13} \mathrm{C}$ NMR shifts and $\pi$ densities

, to possess a $30^{\circ}$ twisted ground state; 11 we believe this to be an artifact due to the excessively low barriers erroneously given by this method. ${ }^{16}$

Methyl substitution at $\mathrm{C}-1$ (or $\mathrm{C}-3$ ) results in an elongation of the adjacent allylic $\mathrm{C}-\mathrm{C}$ bond and shortening of the remote bond (Table I). In valence bond terminology, the canonical structure $\mathbf{2}^{\prime}$ is favored over $\mathbf{2}^{\prime \prime}$ because of the stabilizing effect<smiles>C=CC(C)C</smiles>

of the alkyl group. As a consequence, a methyl group increases the positive charge at the substituted allyl terminus and decreases the charge at the opposite end, as demonstrated by the calculated $\pi$ densities (Table I). The ${ }^{13} \mathrm{C}$ NMR spectra of allyl cations, which show a deshielding of the substituted allylic carbon and a shielding of the opposite terminus, have been interpreted analogously. ${ }^{17}$ Figure 1 shows a linear correlation between the observed ${ }^{13} \mathrm{C}$ NMR chemical shifts ${ }^{18}$ and the calculated $\pi$ densities (charge density at the $\mathrm{p}_{\pi}$ orbital calculated by the Mulliken procedure ${ }^{19}$ ). Regression analysis yields the equation, $\delta=456-450 \pi$ density, and a correlation coefficient $r^{2}=0.961$.

In contrast, bond lengths and ${ }^{13} \mathrm{C}$ NMR chemical shifts remain almost unchanged on substitution at the 2 position.

The sequential widening of the $\mathrm{C}^{1} \mathrm{C}^{2} \mathrm{C}^{3}$ angle in the series $5 \rightarrow 6 \rightarrow 7$ can be attributed to increasing steric strain. The increase of angle $\beta$ from 5 to 6 and of angle $\beta^{\prime}$ from 6 to 7 (Table I) also have steric origins.

Methyl Conformations. The preference of the eclipsed over the staggered conformations of the methyl groups of both crotyl cations 2 and $\mathbf{3}$ has been calculated previously. ${ }^{9} \mathrm{Al}-$ though the differences are not large, methyl groups, not ster-

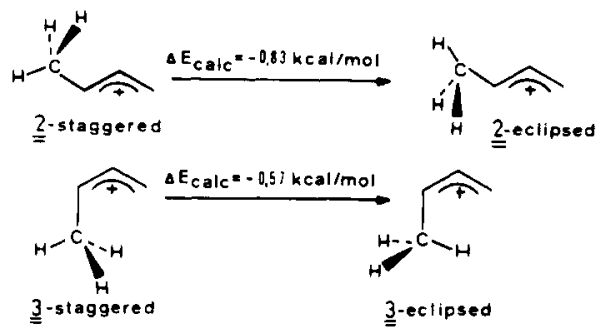

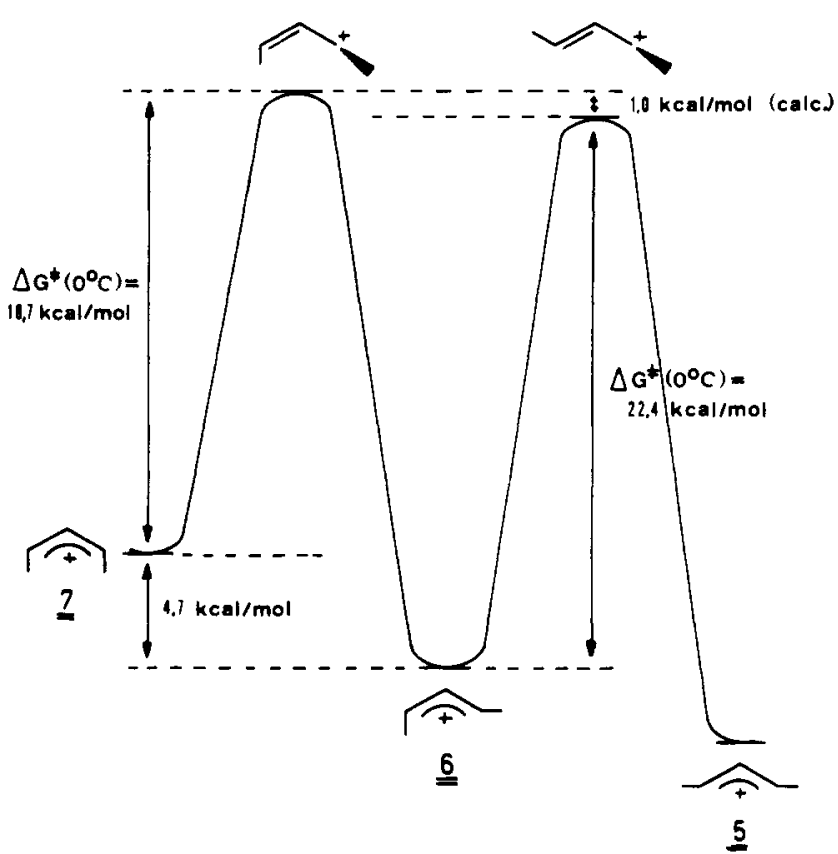

Figure 2. Analysis of relative energies of 1.3-dimethylallyl cations.

ically interacting with other substituents, generally should prefer eclipsed conformations. This conclusion is in accord with the results of the sickle-shaped 1,3-dimethylallyl cation $6 .{ }^{20}$

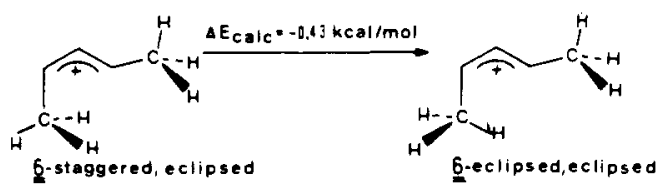

However, for the U-shaped cation 7, the doubly staggered form is indicated to be more stable. ${ }^{20}$ Because of this large energy

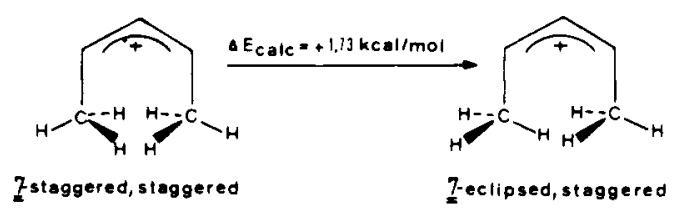

difference, the $s, s$ conformation has been assumed for calculations of all cations with two endo-methyl groups $(12,15,17)$. The $Z, s-E, e$ conformer depicted for 8 (Table I) is $0.5 \mathrm{kcal} / \mathrm{mol}$ more stable than the $Z, e-E, s$ or the $Z, s-E, s$ conformer. Consequently; this conformation was also selected for the calculation of the cations 11, 12, and 16. Rotation of the 3methyl in 9 involves a barrier of $0.1 \mathrm{kcal} / \mathrm{mol}$ and the 2 -methyl and 3 -methyl conformations in cations 13,14 , and 16 were aligned as in 9.

2. Energy. Steric Strain. As previously discussed for the crotyl cations, methyl groups prefer exo-over endo-allyl cation positions. ${ }^{9 a}$ According to Table II, this preference amounts to $3 \mathrm{kcal} / \mathrm{mol}$ and is almost independent of the system. The slightly smaller difference between 13 and 14 can be explained by steric crowding in $\mathbf{1 3}$ due to the three cis-methyl groups. Introduction of a second endo-methyl group increases the strain by $5 \mathrm{kcal} / \mathrm{mol}$ as shown by the examples in the lower part of Table II.

A closely similar value has already been derived from experimental data. Schleyer and Saunders measured the rates of isomerization of 7 to 6 and of 6 to 5 and interpreted the difference of the Arrhenius activation energies $(6.5 \mathrm{kcal} / \mathrm{mol})$ as $\Delta \Delta H_{f}{ }^{\circ}$ of 6 and $7 .^{21}$ In Figure 2 we present a slightly different interpretation of these experimental data. Because of the potentially large experimental error in $E_{\mathrm{u}}, \Delta G^{\neq}$is em- 
Table I. Ab Initio Geometries and Energies (STO-3G) of Methyl-Substituted Allyl Cations ${ }^{a}$

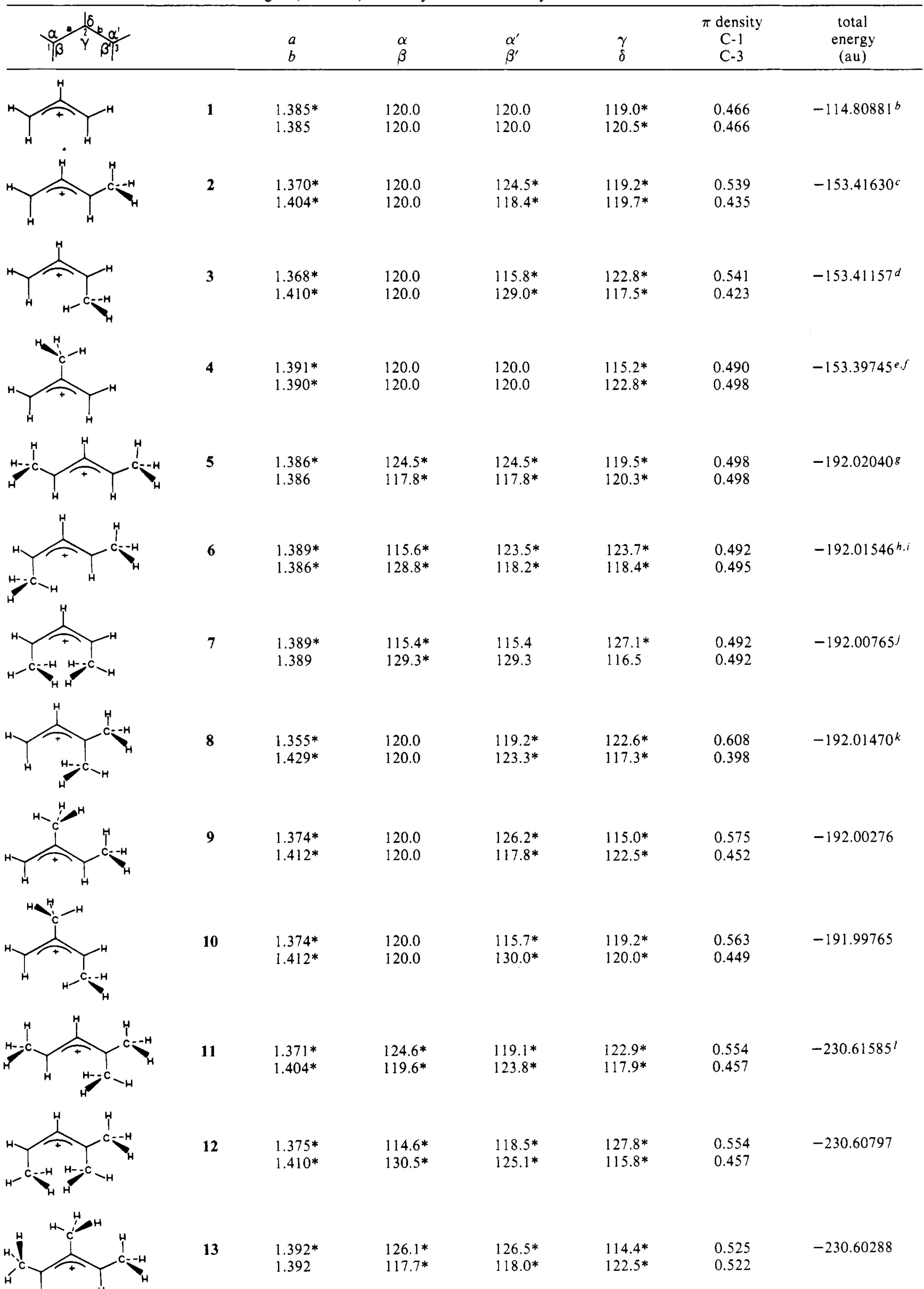




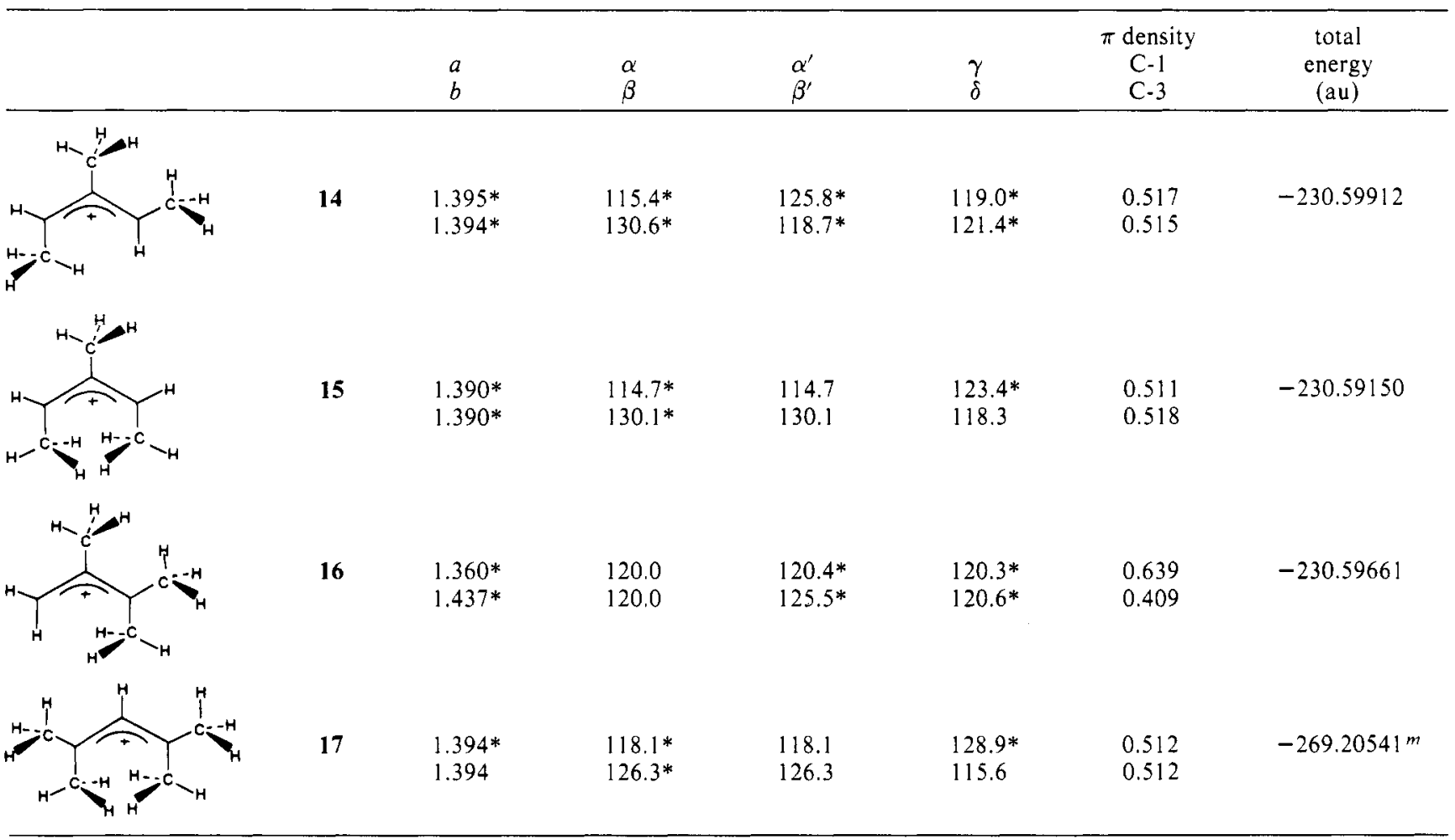

${ }^{a}$ Asterisks signify optimized parameters; values without asterisks were standard or taken from the parent: $\mathrm{C}-\mathrm{CH} 3=1.52 \AA, \mathrm{C}-1-\mathrm{H}=1.10$ $\AA, \mathrm{C}-2-\mathrm{H}=1.084 \AA, \mathrm{H}_{2} \mathrm{C}-\mathrm{H}=1.09 \AA$, tetrahedral angles in $\mathrm{CH}_{3}$ groups. ${ }^{b}$ Complete opt $E=-114.80953:$ ref $7 .{ }^{c} E=-153.41436:$ ref 9a. $E=-153.41377: \operatorname{ref} 12 . E=-153.41560:$ ref $23 .{ }^{d} E=-153.40964:$ ref 9a. $E=-153.40480:$ ref $23 .{ }^{e} E=-153.39761:$ ref $23 . f^{f}$ Complete opt: $\alpha=\alpha^{\prime}=121,6, \beta=\beta^{\prime}=122.0, \mathrm{C}-\mathrm{CH}_{3}=1.530, \mathrm{H}-\mathrm{CH}_{2}=1.088,1.088,1.085, \mathrm{H}-\mathrm{CH}_{2} \mathrm{C}^{2}=110.2,110.2,110.0$; other parameters unchanged; $E=-153.39854 .{ }^{g} E=-192.01528:$ ref $12 .{ }^{h} E=-192.00880:$ ref $12 . E=-192.01358:$ ref $20 .{ }^{i}$ Complete opt: $a=b=1.386$, $\alpha=116.1 \beta=129.3, \alpha^{\prime}=124.3, \beta^{\prime}=119.4, \gamma=123.0, \delta=118.7, \mathrm{CH}_{3}-\mathrm{C}^{1}=1.512, \mathrm{H}-\mathrm{CH}_{2}\left(\mathrm{C}^{1}\right)=1.091,1.091,1.083, \mathrm{H}-\mathrm{CH}_{2}-\mathrm{C}^{1}=108.0$, $108.0,113.5, \mathrm{CH}_{3}-\mathrm{C}^{3}=1.508, \mathrm{H}-\mathrm{CH}_{2}\left(\mathrm{C}^{3}\right)=1.092,1.092,1.085, \mathrm{H}-\mathrm{CH}_{2}-\mathrm{C}^{3}=108.5,108.5,111.6$; other parameters unchanged; $E=$ $-192.01702 .{ }^{j} E=-191.95703: \operatorname{ref} 12 . E=-192.00441: \operatorname{ref} 20 .{ }^{k} E=-192.01036: \operatorname{ref} 12 .{ }^{l} E=-230.60996: \operatorname{ref} 12 .{ }^{m} E=-269.15662:$ ref 12 .

ployed. $\Delta S^{\ddagger}$ is thus assumed to be similar for the two isomerization reactions. Our calculations indicate the transition states not to be equal in energy, as was assumed earlier, ${ }^{21}$ but to differ by $1 \mathrm{kcal} / \mathrm{mol}$ (see Table IV). On this basis, a corrected experimental energy difference of $4.7 \mathrm{kcal} / \mathrm{mol}$, almost identical with the calculated difference $(4.9 \mathrm{kcal} / \mathrm{mol})$, is obtained. Standard geometry calculations significantly overestimated the difference in stability between 6 and 7 (31.4 $\mathrm{kcal} / \mathrm{mol}) .^{12}$

The activation free enthalpies of the stereomutations $15 \rightarrow$ 14 and $14 \rightarrow 13$ differ by $5.5 \mathrm{kcal} / \mathrm{mol},{ }^{22}$ a value similar to the calculated $\Delta H_{f}{ }^{\circ}$ of 14 and $15(4.8 \mathrm{kcal} / \mathrm{mol})$. No correction for the transition states is needed since there are two cis substituents at the double bond of the perpendicular ion in both cases.

Methyl Stabilization. The stabilization of allyl cations by methyl groups can be evaluated from STO-3G energies (Table I) on the basis of isodesmic reactions $1-10$. Stabilization by successive terminal methyl substitution for these steps are 17 , $15,9.5$, and $6 \mathrm{kcal} / \mathrm{mol}$, respectively (eq $1,2,5,7$ ).

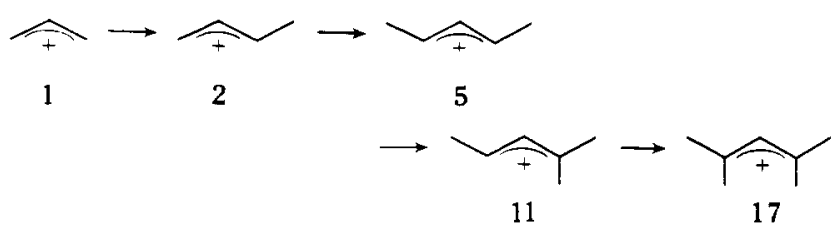

In the last two steps, electronic stabilization is counterbalanced by steric destabilization due to the introduction of endo sub-stituents. Such steric effects are absent if only substitution by exo-methyl groups is considered: eq $1,2,6$, and 8 indicate an electronic stabilization of $17,15,13$, and $11 \mathrm{kcal} / \mathrm{mol}$ for the first, second, third, and fourth terminal methyl group, respectively. If the 1 -methyl allyl cation is further methylated at the 1 or 3 position, there is no significant change in energy as long as the steric strains are identical (eq 3 and 4 ).

As expected, 2-methylation has a smaller effect, $5.3 \mathrm{kcal} /$ $\mathrm{mol}$ in the case of 1 (eq 9) and $1.4 \mathrm{kcal} / \mathrm{mol}$ for 2 -methylation of 5 (eq 10).

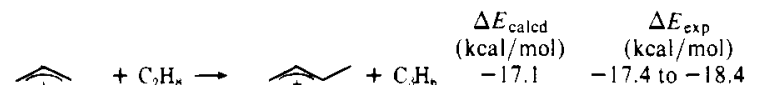

$$
\begin{aligned}
& \widehat{+}+\mathrm{C}_{2} \mathrm{H}_{r} \rightarrow \underset{+}{\widehat{A}}+\mathrm{C}_{3} \mathrm{H}_{b} \quad-15.0 \quad-11.9 \text { to }-14.4
\end{aligned}
$$

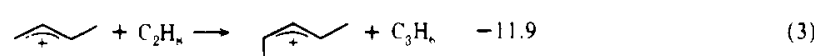

$$
\begin{aligned}
& \widehat{+}+\mathrm{C}_{2} \mathrm{H}_{n} \rightarrow \widehat{\overbrace{}}+\mathrm{C}_{3} \mathrm{H}_{\kappa} \quad-11.4 \quad-10.2 \text { to }-15.4 \\
& \widehat{\widehat{A}}+\mathrm{C}_{2} \mathrm{H}_{n} \rightarrow \widetilde{\widehat{+}}+\mathrm{C}_{3} \mathrm{H}_{n} \quad-9.5 \quad-7.4 \text { to }-8.9 \\
& \widehat{\widehat{P}}+\mathrm{C}_{2} \mathrm{H}_{8} \rightarrow \widehat{\widehat{P}}+\mathrm{C}_{3} \mathrm{H}_{6} \quad-13.1 \quad-6.4 \text { to }-10.6 \quad \text { (6) }
\end{aligned}
$$

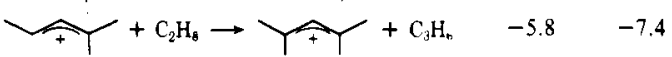

$$
\begin{aligned}
& \widehat{\curvearrowright Y}+\mathrm{C}_{2} \mathrm{H}_{4} \rightarrow \widehat{Y}+\mathrm{C}_{3} \mathrm{H}_{\mathrm{h}} \quad-10.8 \\
& \widehat{\curvearrowright}+\mathrm{C}_{2} \mathrm{H}_{8} \rightarrow \widehat{\mathrm{A}}+\mathrm{C}_{\mathrm{H}} \mathrm{H}_{\mathrm{n}}-5.3 \quad-10.4
\end{aligned}
$$

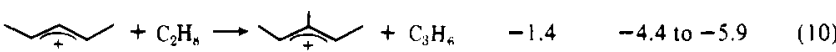

Comparison with Gas-Phase Data. The stabilization energies defined by eq $1-10$ can alternatively be derived from gas-phase data. Their interpretation is problematic, however, since in 
Table II. Relative Energy of Stereoisomeric Allyl Cations

\begin{tabular}{|c|c|c|c|c|}
\hline 2-R & $3-R$ & $\mathrm{H}$ & $\underbrace{2}$ & $\begin{array}{c}\Delta E_{\text {calcd }} \\
(\mathrm{kcal} / \\
\text { mol })\end{array}$ \\
\hline $\mathrm{H}$ & $\mathrm{H}$ & 2 & 3 & 3.0 \\
\hline $\mathrm{CH}_{3}$ & $\mathrm{H}$ & 9 & 10 & 3.2 \\
\hline $\mathrm{H}$ & $\mathrm{CH}_{3}$ & 5 & 6 & 3.1 \\
\hline $\mathrm{CH}_{3}$ & $\mathrm{CH}_{3}$ & 13 & 14 & 2.3 \\
\hline $2-R$ & $3-R$ & & $\mathrm{CH}_{3}$ & $\begin{array}{c}\Delta E_{\text {calcd }} \\
(\mathrm{kcal} / \\
\mathrm{mol})\end{array}$ \\
\hline $\mathrm{H}$ & $\mathrm{H}$ & 6 & 7 & 4.9 \\
\hline $\mathrm{CH}_{3}$ & $\mathrm{H}$ & 14 & 15 & 4.8 \\
\hline $\mathrm{H}$ & $\mathrm{CH}_{3}$ & 11 & 12 & 5.0 \\
\hline
\end{tabular}

most cases inconsistent experimental results (see Scheme I) lead to differing stabilization energies.

For eq $1-8$ (terminal methyl substitution), the agreement between calculated and experimental numbers appears to be very good. The maximum deviations are only $-2.5 \mathrm{kcal} / \mathrm{mol}$ (eq 6) and $+1.6 \mathrm{kcal} / \mathrm{mol}$ (eq 7 ) and these may be due to a slight inaccuracy of the experimental $\Delta H_{\mathrm{f}}{ }^{\circ}$ value in 11 since the deviations are in opposite directions. An error in the calculated energy of 11 is improbable, because 11 fits very well in the series of the other calculated systems, as shown above.

2-Methyl substitution is generally calculated to be less stabilizing than experimentally observed; in these cases, a systematic error of $3-5 \mathrm{kcal} / \mathrm{mol}$ may be present in the calculations. Equations $1-10$ can be generalized by eq 11 . Since $\Delta H$ of eq 11 can be calculated from STO-3G energies, ${ }^{24}$ one

$$
\widehat{F}+n \mathrm{C}_{3} \mathrm{H}_{8} \rightarrow \widehat{\leftarrow}^{\left(\mathrm{CH}_{3}\right)_{n}}+n \mathrm{C}_{2} \mathrm{H}_{6}
$$

can obtain $\Delta H_{\mathrm{f}}{ }^{\circ}$ of the methyl-substituted allyl cations from the calculated $\Delta H$ and the experimental heat of formation of the parent allyl cation, ${ }^{2}$ ethane, and propane. ${ }^{25}$ Equation 12 ,

$$
\begin{aligned}
\Delta H_{\mathrm{f}}{ }^{\circ}(\mathrm{kcal} / \mathrm{mol})=627.49 & E_{\text {total }}(\mathrm{au}) \\
& +24204.125 n+72267.38
\end{aligned}
$$

which is derived on this basis, was used to calculate the heats of formation of the methyl-substituted allyl cations (Scheme I). Since the agreement between the calculated $\Delta H_{\mathrm{f}}{ }^{\circ}$ values and the available experimental numbers is quite good, it can be assumed that the predictions in Scheme I are also reliable.

Comparison with Solvolysis Data. Solvolysis reactions of allylic chlorides and allylic $p$-nitrobenzoates have been shown to proceed via allyl cations in aqueous formic acid and aqueous acetone, respectively. ${ }^{27}$ Table III shows relative rate constants and relative activation free enthalpies of these reactions. In Figure 3, $\Delta \Delta G^{\neq}$is plotted against the $\Delta H_{f}{ }^{\circ}$ difference of the allyl cations and the corresponding precursors. A slope of 0.52 for solvolysis of the allyl chlorides in aqueous formic acid and of 0.41 for the allylic $p$-nitrobenzoates in aqueous acetone indicates that the carbocation character is only partially developed in the solvolysis transition states. Recently, Arnett, Petro, and Schleyer reported a linear correlation of the heats of ionization of various alkyl halides under superacidic conditions with the corresponding activation free energies of the solvolysis reactions. ${ }^{29}$ The slope of the line (0.89) was larger than in our cases; the difference may be due to solvation effects in superacid solutions.

B. Perpendicular Allyl Cations. The calculated total energies of perpendicular allyl cations are summarized in Table IV. The
Scheme I. Calculations of $\Delta H_{\mathrm{f}}{ }^{\circ}$ of Methyl-Substituted Allyl Cations (Experimental Numbers in Parentheses)

$$
\begin{aligned}
& n=0 \text { 尺 } \\
& 226 \\
& \text { (226)므 }
\end{aligned}
$$

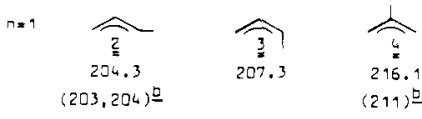

$$
\begin{aligned}
& \pi=2 \text { } \\
& \begin{array}{lll}
184.7 & 187.8 & 192.7
\end{array} \\
& \text { רิ } \\
& \overbrace{\substack{12 \\
175.6}}^{\substack{19 \\
178.8 \\
(176)}} \\
& n=5 \quad \underset{\substack{20 \\
155.39}}{(157)} \\
& \text { ר్ }
\end{aligned}
$$

$a$ Reference compound. $b$ Reference 2. $c$ Reference 26. $d$ Estimated from 17 and the difference 12-14. e Estimated from 17 and the difference 12-15. $f$ Estimated from 18 and the difference 11-17.

stabilizing effect of methyl on the cationic center is demonstrated by eq 13 . Comparison with eq 14 shows that the cal-

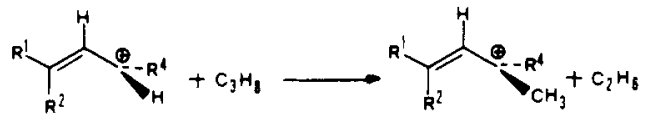

\begin{tabular}{lllc}
\multicolumn{1}{c}{$\mathrm{R}^{1}$} & $\mathrm{R}^{2}$ & $\mathrm{R}^{4}$ & $\begin{array}{c}\Delta E_{\text {calcd }} \\
(\mathrm{kcal} / \mathrm{mol})^{24}\end{array}$ \\
\hline $\mathrm{H}$ & $\mathrm{H}$ & $\mathrm{H}$ & -24.2 \\
$\mathrm{CH}$ & $\mathrm{H}$ & $\mathrm{H}$ & -23.6 \\
$\mathrm{H}$ & $\mathrm{CH}_{3}$ & $\mathrm{H}$ & -23.3 \\
$\mathrm{CH}_{3}$ & $\mathrm{CH}_{3}$ & $\mathrm{H}$ & -23.1 \\
$\mathrm{H}$ & $\mathrm{H}$ & $\mathrm{CH}_{3}$ & -20.1 \\
$\mathrm{CH}_{3}$ & $\mathrm{H}$ & $\mathrm{CH}_{3}$ & -18.8 \\
\hline
\end{tabular}

culated $\Delta E$ of eq 13 is identical with the stability difference of the ethyl and 2-propyl cation $\left(\mathrm{R}^{4}=\mathrm{H}\right.$, eq 13) or the 2-propyl

$$
\begin{array}{r}
\mathrm{R}=\mathrm{H} \Delta E_{\text {calcd }}=-24.7 \mathrm{kcal} / \mathrm{mol} ; 30 \\
\Delta E_{\text {exp }}=-22.4 \mathrm{kcal} / \mathrm{mol}^{25,31} \\
\mathrm{R}=\mathrm{CH}_{3} \Delta E_{\text {calcd }}=-19.6 \mathrm{kcal} / \mathrm{mol} ; \\
\Delta E_{\text {exp }}=-18.4 \mathrm{kcal} / \mathrm{mol}
\end{array}
$$

and tert -butyl cation $\left(\mathrm{R}^{4}=\mathrm{CH}_{3}\right.$, eq 13$)$. Since this energy difference is that obtained experimentally, we can conclude that $\Delta E$ of eq 13 is also in agreement with experiment. Sub-

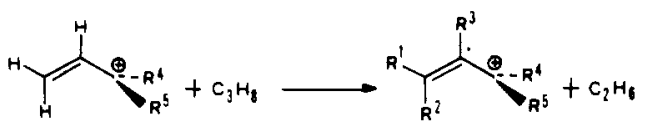

\begin{tabular}{lllllll}
\multicolumn{1}{c}{$\mathrm{R}^{1}$} & $\mathrm{R}^{2}$ & $\mathrm{R}^{3}$ & $\mathrm{R}^{4}$ & \multicolumn{1}{c}{$\mathrm{R}^{5}$} & $\begin{array}{c}\Delta E_{\text {calcd }} \\
(\mathrm{kcal} / \mathrm{mol})\end{array}$ \\
\hline $\mathrm{CH}_{3}$ & $\mathrm{H}$ & $\mathrm{H}$ & $\mathrm{H}$ & $\mathrm{H}$ & -7.7 & $(15 \mathrm{a})$ \\
$\mathrm{H}$ & $\mathrm{CH}_{3}$ & $\mathrm{H}$ & $\mathrm{H}$ & $\mathrm{H}$ & -6.9 & $(15 \mathrm{~b})$ \\
$\mathrm{CH}_{3}$ & $\mathrm{H}$ & $\mathrm{H}$ & $\mathrm{CH}_{3}$ & $\mathrm{H}$ & -7.1 & $(15 \mathrm{c})$ \\
$\mathrm{H}$ & $\mathrm{CH}_{3}$ & $\mathrm{H}$ & $\mathrm{CH}_{3}$ & $\mathrm{H}$ & -6.1 & $(15 \mathrm{~d})$ \\
$\mathrm{CH}_{3}$ & $\mathrm{H}$ & $\mathrm{H}$ & $\mathrm{CH}_{3}$ & $\mathrm{CH}_{3}$ & -5.8 & $(15 \mathrm{e})$ \\
$\mathrm{H}$ & $\mathrm{H}$ & $\mathrm{CH}_{3}$ & $\mathrm{CH}_{3}$ & $\mathrm{CH}_{3}$ & -3.8 & $(15 \mathrm{f})$ \\
\hline
\end{tabular}


Table III. Relative Rate Constarits and Activation Free Energies of Various Allylic Chlorides ${ }^{a}$ and $p$-Nitrobenzoates ${ }^{b}$

\begin{tabular}{|c|c|c|c|c|}
\hline & $k_{\text {rel }}$ & $\Delta \Delta G^{\ddagger}$ & $\begin{array}{c}\Delta H_{\mathrm{f}}{ }^{\circ} \\
\text { (precur- } \\
\text { sor) }{ }^{c}\end{array}$ & $\begin{array}{c}\Delta H_{\mathrm{f}}{ }^{\circ} \\
\text { (cation) }^{d} \\
-\Delta H_{\mathrm{f}}{ }^{\circ} \\
\text { (prec) }^{2}\end{array}$ \\
\hline $\mathrm{CH}_{2}=\mathrm{CHCH}_{2} \mathrm{Cl}$ & 1.0 & 0.0 & -1.6 & 227.6 \\
\hline $\begin{array}{c}\mathrm{CH}_{2}=\mathrm{C}\left(\mathrm{CH}_{3}\right)- \\
\mathrm{CH}_{2} \mathrm{Cl}\end{array}$ & 0.5 & 0.44 & -10.1 & 226.2 \\
\hline $\begin{array}{c}\mathrm{CH}_{2}=\mathrm{CHCH}- \\
\left(\mathrm{CH}_{3}\right) \mathrm{Cl}\end{array}$ & $5.67 \times 10^{3}$ & -5.44 & -10.2 & 214.5 \\
\hline $\begin{array}{c}\mathrm{CH}_{2}=\mathrm{CHC}- \\
\left(\mathrm{CH}_{3}\right)_{2} \mathrm{Cl}\end{array}$ & $8 \times 10^{7}$ & -11.45 & -18.3 & 206.6 \\
\hline$\underset{\mathrm{CH}_{2} \mathrm{Cl}}{\mathrm{CH}_{3} \mathrm{CH}}=\mathrm{CH}-$ & $3.55 \times 10^{3}$ & -5.14 & -9.5 & 213.8 \\
\hline $\begin{array}{c}\left(\mathrm{CH}_{3}\right)_{2} \mathrm{C}=\mathrm{CH}- \\
\mathrm{CH}_{2} \mathrm{Cl}\end{array}$ & $1.5 \times 10^{7}$ & -10.40 & -17.0 & 205.3 \\
\hline $\begin{array}{l}\mathrm{CH}_{2}=\mathrm{CHC}- \\
\left(\mathrm{CH}_{3}\right)_{2} \mathrm{OPNB}\end{array}$ & 1.0 & 0.0 & -50.2 & 238.5 \\
\hline $\begin{array}{c}\mathrm{CH}_{2}=\mathrm{C}\left(\mathrm{CH}_{3}\right) \mathrm{C}- \\
\left(\mathrm{C} \mathrm{H}_{3}\right)_{2} \mathrm{OPNB}\end{array}$ & 0.72 & 0.19 & -58.7 & 241.4 \\
\hline $\begin{array}{r}\mathrm{CH}_{3} \mathrm{CH}=\mathrm{CHC}- \\
\left(\mathrm{CH}_{3}\right)_{2} \mathrm{OPNB}\end{array}$ & $2.2 \times 10^{3}$ & -4.54 & -58.1 & 228.7 \\
\hline $\begin{array}{c}\left(\mathrm{CH}_{3}\right)_{2} \mathrm{C}=\mathrm{CHC}- \\
\left(\mathrm{CH}_{3}\right)_{2} \mathrm{OPNB}\end{array}$ & $2.3 \times 10^{4}$ & -5.93 & -65.6 & 225.8 \\
\hline
\end{tabular}

$a^{a}$ Rate constants in $0.5 \%$ aqueous formic acid at $44.6^{\circ} \mathrm{C}$ : ref $27 \mathrm{a}$. ${ }^{b}$ Rate constants in $80 \%$ aqueous acetone at $25^{\circ} \mathrm{C}$ : ref $27 \mathrm{~b}$. ${ }^{c}$ Estimated from group increments for the allyl chlorides and the corresponding alcohols for the nitrobenzoates: ref $28{ }^{d} \Delta H^{\circ}$ (caled) from Scheme I.

Table IV. Ab Initio Calculations (STO-3G) on Perpendicular Allyl Cations $^{a}$

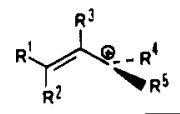

\begin{tabular}{llllll}
\hline $\mathrm{R}^{1}$ & $\mathrm{R}^{2}$ & $\mathrm{R}^{3}$ & $\mathrm{R}^{4}$ & $\mathrm{R}^{5}$ & $\begin{array}{c}\text { total energy } \\
(\mathrm{au})\end{array}$ \\
\hline $\mathrm{H}$ & $\mathrm{H}$ & $\mathrm{H}$ & $\mathrm{H}$ & $\mathrm{H}$ & -114.75468 \\
$\mathrm{H}$ & $\mathrm{H}$ & $\mathrm{H}$ & $\mathrm{CH}_{3}$ & $\mathrm{H}$ & -153.37342 \\
$\mathrm{CH}_{3}$ & $\mathrm{H}$ & $\mathrm{H}$ & $\mathrm{H}$ & $\mathrm{H}$ & -153.34716 \\
$\mathrm{H}$ & $\mathrm{CH}$ & $\mathrm{H}$ & $\mathrm{H}$ & $\mathrm{H}$ & -153.34596 \\
$\mathrm{H}$ & $\mathrm{H}$ & $\mathrm{H}$ & $\mathrm{CH}_{3}$ & $\mathrm{CH}_{3}$ & -191.98571 \\
$\mathrm{CH}_{3}$ & $\mathrm{CH}$ & $\mathrm{H}$ & $\mathrm{H}$ & $\mathrm{H}$ & $-191.93376^{b}$ \\
$\mathrm{CH}_{3}$ & $\mathrm{H}$ & $\mathrm{H}$ & $\mathrm{CH}_{3}$ & $\mathrm{H}$ & $-191.96502^{c}$ \\
$\mathrm{H}$ & $\mathrm{CH}$ & $\mathrm{H}$ & $\mathrm{CH}_{3}$ & $\mathrm{H}$ & -191.96339 \\
$\mathrm{CH}_{3}$ & $\mathrm{CH}$ & $\mathrm{H}$ & $\mathrm{CH}_{3}$ & $\mathrm{H}$ & -230.55075 \\
$\mathrm{CH}_{3}$ & $\mathrm{H}$ & $\mathrm{H}$ & $\mathrm{CH}_{3}$ & $\mathrm{CH}_{3}$ & -230.57527 \\
$\mathrm{H}$ & $\mathrm{H}$ & $\mathrm{CH}$ & $\mathrm{CH}_{3}$ & $\mathrm{CH}_{3}$ & -230.57196 \\
\hline
\end{tabular}

a All calculations carried out with partial geometry optimization. Bond angle $R^{4} C^{3} R^{5}$ was optimized if either $R^{4}$ or $R^{5}$ were methyl. All other parameters were taken from the completely optimized geometry of the perpendicular parent system (ref 7). ${ }^{b}$ Complete opt $E=$ -191.93661 au. ${ }^{c}$ Complete opt $E=-191.96582$ au.

stitution of the formally uncharged double bond has a smaller effect (eq 15, 16). A trans-methyl group (position $\mathrm{R}^{\prime}$ ) stabilizes primary, secondary, and tertiary cations by $7.7,7.1$, and $5.8 \mathrm{kcal} / \mathrm{mol}$, respectively (eq $15 \mathrm{a}, \mathrm{c}, \mathrm{e}$ ). The effect of a cismethyl group $\left(\mathrm{R}^{2}=\mathrm{CH}_{3}\right)$ is approximately $1 \mathrm{kcal} / \mathrm{mol}$ smaller (eq 15b,d); a 2-methyl group $\left(\mathrm{R}^{3}=\mathrm{CH}_{3}\right)$ stabilizes perpendicular allyl cations by $3.8 \mathrm{kcal} / \mathrm{mol}$ (eq $15 \mathrm{f}$ ). Equation 16

\begin{tabular}{lc}
$\mathrm{R}_{4}$ & $\begin{array}{c}\Delta E_{\text {calcd }} \\
(\mathrm{kcal} / \mathrm{mol})\end{array}$ \\
$\mathrm{H}_{\mathrm{CH}}$ & -4.7 \\
$\mathrm{CH}_{3}$ & -4.5 \\
\hline
\end{tabular}

Table V. Theoretical Evaluations of the Rotational Barrier of the Allyl Cation

\begin{tabular}{cllr}
\hline $\begin{array}{c}\Delta E^{\ddagger} \\
(\mathrm{kcal} / \mathrm{mol})\end{array}$ & \multicolumn{1}{c}{ geometry } & ref \\
\hline 42 & ab initio & standard & 3 \\
11 & CNDO & optimized & 4 \\
29 & NNDO & part. opt & 5 \\
38 & Dewar & part. opt & 5 \\
14 & MINDO/2 & not defined & 6 \\
19.7 & INDO & part. opt & 11 \\
17.3 & MINDO/3 & part. opt & 32 \\
34.4 & ab initio (STO-3G) & optimized & 7 \\
35.0 & ab initio (4-31G) & STO-3G opt & 7 \\
34.8 & ab initio (6-31G*) & STO-3G opt & 7 \\
34.0 & ab initio (4-31G) & $4-31 \mathrm{G}$ opt & 36 \\
36.6 & ab initio (4-31G/MP2) & $4-31 \mathrm{G}$ opt & 36 \\
34.1 & ab initio (4-31G/MP3) & $4-31 \mathrm{G}$ opt & 36 \\
33.2 & ab initio (4-31G/MP4/DQ) & $4-31 \mathrm{G} \mathrm{opt}$ & 36 \\
33.8 & ab initio (4-31G/MP4/SDQ) & $4-31 \mathrm{G} \mathrm{opt}$ & 36 \\
34.0 & ab initio (6-31G*) & $4-31 \mathrm{G} \mathrm{opt}$ & 36 \\
\hline
\end{tabular}

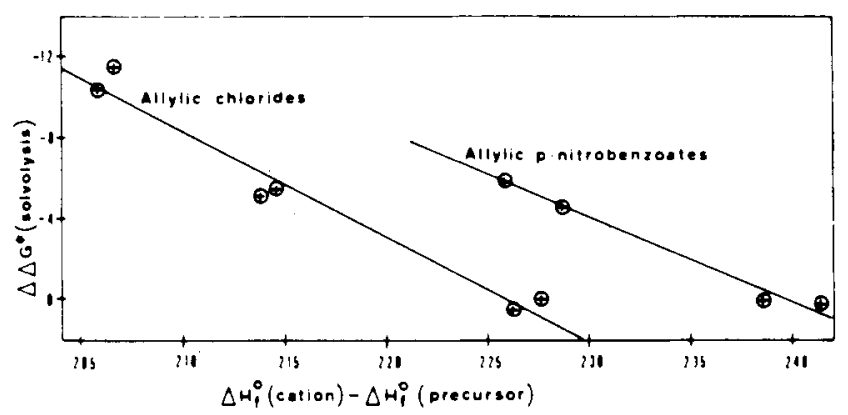

Figure 3. Correlation between activation free enthalpies of the solvolysis reactions of allylic chlorides and $p$-nutrobenzoates and gas-phase stabilities of the cations.

shows that a stabilization of $4.6 \mathrm{kcal} / \mathrm{mol}$ by a trans-methyl is expected if position $R^{2}$ is already methyl substituted.

C. Rotational Barriers. The rotational barrier of the parent allyl cation has previously been calculated by a variety of methods; values from 11 to $42 \mathrm{kcal} / \mathrm{mol}$ have been obtained (Table V). Because of the low chemical stability of the parent allyl cation, no experimental data are available. Barriers of 11.5 and $7.8 \mathrm{kcal} / \mathrm{mol}$ have been calculated by MINDO $/ 3$ for the $(Z, Z)$-1,3-dimethylallyl cation (7) and the 1,1,3,3-tetramethylallyl cation (17), ${ }^{10}$ respectively. Experimentally, much larger activation free energies of 18.7 and $17.5 \mathrm{kcal} / \mathrm{mol}$ have been observed. ${ }^{21,33}$ INDO gives a rotational barrier of 4.1 $\mathrm{kcal} / \mathrm{mol}$ for the 1,1-dimethylallyl cation 8 , which seems to be much too low when one considers the experimental value of $11.7 \mathrm{kcal} / \mathrm{mol}$ for $\mathbf{1 6 . 2 2}$

Based on thermodynamic data of allyl cations and the experimentally known rotational barrier of 16 , a rotation barrier of $38-43 \mathrm{kcal} / \mathrm{mol}$ has been estimated for the parent allyl cation, ${ }^{34}$ but this number is too high due to the use of an older heat of formation for the allyl cation. The presently accepted value ${ }^{35}$ yields an estimate, calculated by using the same procedure (eq 17) of $24.7-25.7 \mathrm{kcal} / \mathrm{mol}(11.7+12+1-2$

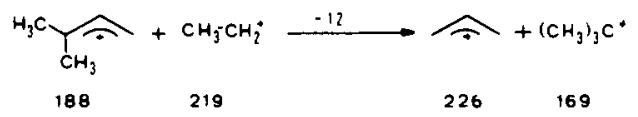

$\mathrm{kcal} / \mathrm{mol}$ ). Another estimate of the rotational barrier of the allyl cation from experimental data was made by Allinger and Siefert. ${ }^{11}$ Applying least squares to a series of experimentally known rotational barriers, they concluded that a methyl group at the rotating carbon lowers the barrier by $6.6 \mathrm{kcal} / \mathrm{mol}$, whereas a methyl group at the nonrotating terminal carbon 


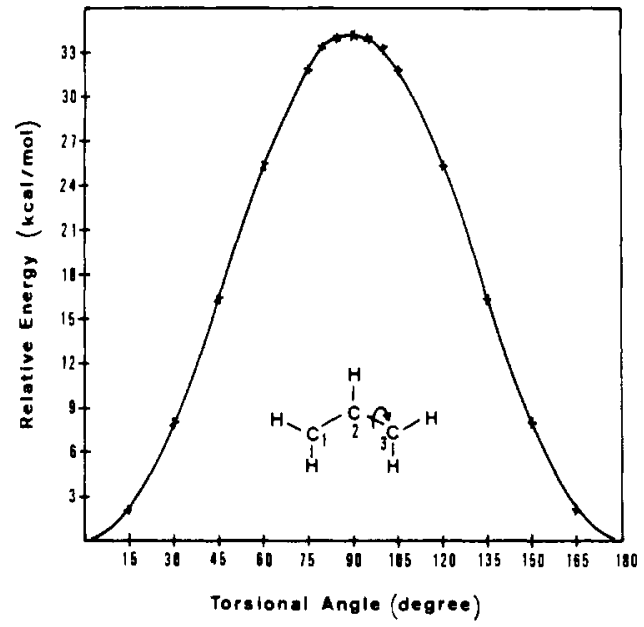

Figure 4. Energy of the allyl cation as a function of the torsional angle of the planes $\mathrm{HC}^{1} \mathrm{C}^{2}$ and $\mathrm{HC}^{3} \mathrm{H}$.

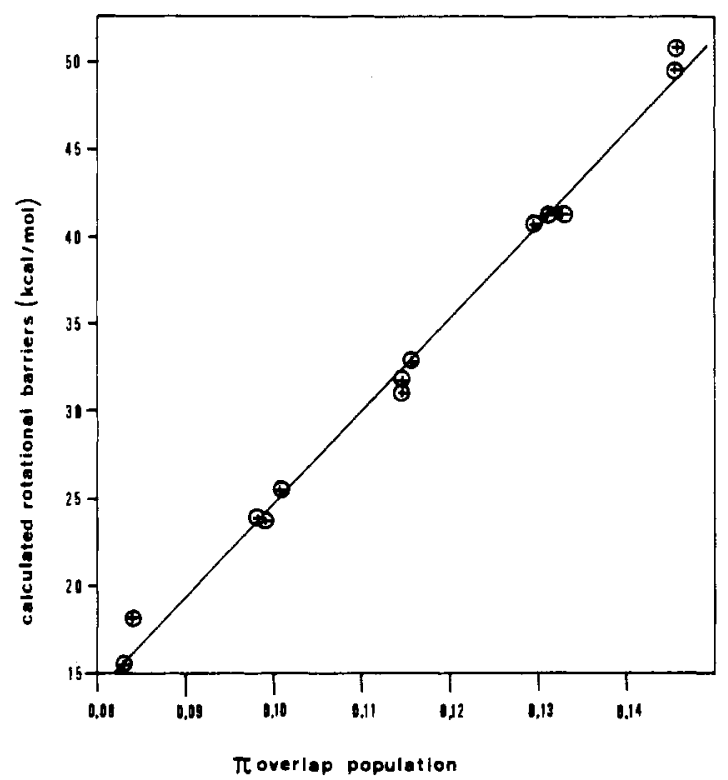

Figure 5. Correlation between calculated rotational barriers and $\pi$-overlap population.

raises the barrier by $3.2 \mathrm{kcal} / \mathrm{mol}$. Steric effects were also considered. A barrier of $27.9 \mathrm{kcal} / \mathrm{mol}$ was deduced for the parent allyl cation in solution. While Allinger's assumption of a constant increment for sequential methyl substitution is not accurate, cancellation of errors led to a value which is in reasonable accord with our conclusions.

Figure 4 shows the energy of the allyl cation as a function of the torsional angle. At each point, a complete optimization has been carried out. It can be seen from Figure 4 that the $90^{\circ}$ twisted form corresponds to the energy maximum. Therefore, the rotational barriers given in Table VI have been calculated as the energy differences between the planar and perpendicular conformations of the allyl cations (from Tables I and IV). Stabilization energies from the isodesmic reactions $13-16$ were used to estimate the energies of the perpendicular cations whose values are not given in Table IV.

Table VI shows that terminal methyls facilitate the rotation of the adjacent allylic bond and raise the barrier for the remote one. The reason is indicated by the comparison of the isodesmic reactions $1-8$ and 13-16: methyl at the rotating end stabilizes the transition state $(20-24 \mathrm{kcal} / \mathrm{mol})$ more than the ground state $(6-17 \mathrm{kcal} / \mathrm{mol})$, while methyl at the nonrotating end

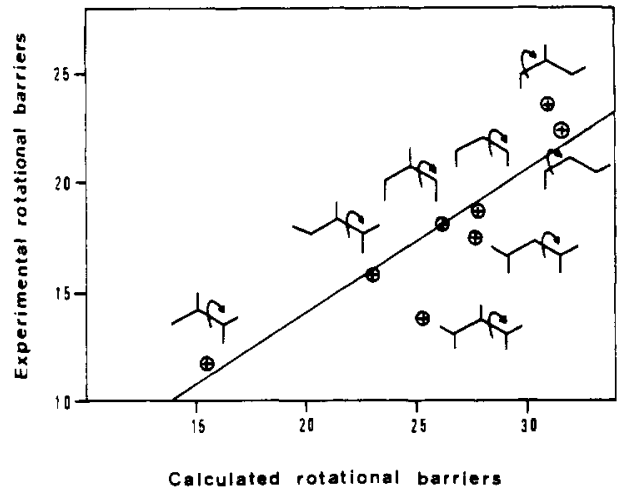

Figure 6. Correlation between calculated and experimental rotational barriers $(\mathrm{kcal} / \mathrm{mol})$.

stabilizes the ground state $(6-17 \mathrm{kcal} / \mathrm{mol})$ better than the transition state $(4-7 \mathrm{kcal} / \mathrm{mol})$. Figure 5 shows a linear correlation $\left(r^{2}=0.990\right)$ of the Mulliken $\pi$ overlap population of the originally $\mathrm{p}_{\pi}$ orbitals in the planar form with the calculated barriers. Only allyl cations with one endo-methyl were employed in Figure 5 so that steric effects cancel. Regression analysis gives eq 18 .

rotational barrier $(\mathrm{kcal} / \mathrm{mol})$

$$
=266.2 \pi \text { overlap population }-28.6
$$

Interestingly the intercept of eq 18 does not equal zero. This implies that, in the absence of $\pi$ overlap, the allyl cation would prefer the perpendicular conformation, where the cationic center would be stabilized by hyperconjugation with the $\mathrm{C}-\mathrm{H}$ and the $\mathrm{C}-\mathrm{C} \sigma$-bonds.

In Figure 6 the experimental rotational barriers are plotted against the calculated values. Except for the pentamethylallyl cation 20, where the calculated value is based on several assumptions and therefore not as reliable, a linear correlation between calculated and experimental rotational barriers is found. Deviations are within experimental error. However, calculated and experimental values are not identical. Is this due to an artifact of our calculations? Higher level calculations with and without correlation do not change the barrier of the parent allyl cation by more than $1 \mathrm{kcal} / \mathrm{mol}$ (Table $\mathrm{V}$ ). ${ }^{36}$ Therefore we interpret the differences between the calculated and observed barriers as being due to a solvation effect. The transition state, with the charge less delocalized, experiences a stronger solvation effect than the planar cation. This interpretation is in accord with Arnett and Petro's demonstration of a solvent effect in the ionization of alkyl halides in superacid media. ${ }^{37}$ Neglecting 20, the graph of Figure 6 is represented by eq 19 .

rotational barrier in soln $(\mathrm{kcal} / \mathrm{mol})$

$$
=0.2+0.69 \text { calcd barrier }
$$

On this basis we predict an activation free energy of 23.7 $\mathrm{kcal} / \mathrm{mol}$ for the rotation of a methylene group of the parent allyl cation in superacid solution.

It should be mentioned that rotation of one allylic bond is not the only stereomutation mechanism possible. Ring closure to a cyclopropyl cation followed by ring opening has been predicted for the 2-methylallyl cation $4^{38}$

D. Resonance Energy. In view of a recent discussion,,$^{39}$ we wish to emphasize the relationship between the actual energy and the resonance energy of a system. Resonance energy has been defined as the quantity obtained by subtracting the actual energy of a molecule from that of the most stable contributing structure ${ }^{40}$ If we accept this definition, then the perpendicular allyl cation can be used as a model for the "nonresonating allyl cation". ${ }^{11}$ After correcting for steric effects, the values in the 
Table VI. Rotational Barriers $(\mathrm{kcal} / \mathrm{mol})$ and Mulliken $\pi$ Overlap Populations of Allyl Cations ${ }^{a}$

\begin{tabular}{|c|c|c|c|c|c|}
\hline system & $\pi \mathrm{C}^{1} \mathrm{C}^{2}$ & $\begin{array}{c}\text { calcd } \\
\text { barriers } \\
\mathrm{C}^{1}-\mathrm{C}^{2}\end{array}$ & $\pi \mathrm{C}^{2} \mathrm{C}^{3}$ & $\begin{array}{c}\text { calcd } \\
\text { barrier } \\
\mathrm{C}^{2}-\mathrm{C}^{3} \\
\end{array}$ & $\Delta G^{\ddagger}(\operatorname{exptl})$ \\
\hline 1 & 0.2332 & 34.0 & 0.2332 & 34.0 & \\
\hline 2 & 0.2626 & 43.4 & 0.2006 & 26.9 & \\
\hline 3 & 0.2656 & 41.2 & 0.1964 & 23.9 & \\
\hline 4 & 0.2308 & $35.5^{b}$ & 0.2324 & $35.5^{b}$ & \\
\hline 5 & 0.2310 & 34.8 & 0.2310 & 34.8 & \\
\hline 6 & 0.2296 & 31.7 & 0.2312 & 32.7 & $22.4^{c}$ \\
\hline 7 & 0.2308 & 27.8 & 0.2308 & 27.8 & $18.7^{\circ}$ \\
\hline 8 & 0.2916 & 50.8 & 0.1678 & 18.2 & \\
\hline 9 & 0.2628 & $44.5^{b}$ & 0.1980 & $27.0^{b}$ & \\
\hline 10 & 0.2622 & $41.3^{b}$ & 0.1992 & $23.8^{b}$ & \\
\hline 11 & 0.2590 & 40.8 & 0.2008 & 25.5 & \\
\hline 12 & 0.2588 & $35.7^{b}$ & 0.1988 & $21.5^{b}$ & \\
\hline 13 & 0.2308 & $33.3^{b}$ & 0.2298 & $33.3^{b}$ & \\
\hline 14 & 0.2298 & $31.0^{b}$ & 0.2292 & $31.0^{b}$ & $23.6^{d}$ \\
\hline 15 & 0.2310 & $26.2^{b}$ & 0.2326 & $26.2^{b}$ & $18.1^{d}$ \\
\hline 16 & 0.2908 & $49.4^{b}$ & 0.1662 & 15.5 & $11.7^{d}$ \\
\hline 17 & 0.2276 & $27.7^{b}$ & 0.2276 & $27.7^{b}$ & $17.5^{e}$ \\
\hline 18 & & $38.2^{b}$ & & $23.0^{b}$ & $15.8^{d}$ \\
\hline 19 & & $33.4^{b}$ & & $18.2^{b}$ & \\
\hline 20 & & $25.3^{b}$ & & $25.3^{b}$ & $13.8^{d}$ \\
\hline
\end{tabular}

${ }^{a}$ For carbon numbering, see Table I. ${ }^{b}$ Calculated by the formula: barrier $=260-4.6 n-$ stab. energy (perp cation) $-\Delta H_{\mathrm{f}}{ }^{\circ}($ planar cation), with $n=$ number of methyls and the following stab energies, $\mathrm{R}^{4}: 24.2 ; \mathrm{R}^{4}+\mathrm{R}^{5}: 44.3 ; \mathrm{R}^{3}: 3.8 ; \mathrm{R}^{1}$ or $\mathrm{R}^{2}: 7.7,7.1$, and 5.8 for primary, secondary, and tertiary cations, respectively. $\mathrm{R}^{1}+\mathrm{R}^{2}$ : values above $+4.6 \mathrm{kcal} / \mathrm{mol}$. For each two cis substituents on the double bond: $-1 \mathrm{kcal} / \mathrm{mol} .{ }^{c} \Delta G^{\neq}$ $\left(0^{\circ} \mathrm{C}\right)$ calculated from the Arrhenius activation parameters in ref $21 .{ }^{d}$ Reference $22 .{ }^{e} \Delta G^{\ddagger}\left(0^{\circ} \mathrm{C}\right)$ calculated from the Arrhenius activation parameters in ref 33.

fourth column of Table VI can be taken to be the resonance energies.

In unsymmetrical systems, like $\mathbf{8}$, where the canonical structures have a large energy difference, the resonance energy (as defined above) is relatively small $(18.2 \mathrm{kcal} / \mathrm{mol}), 42$

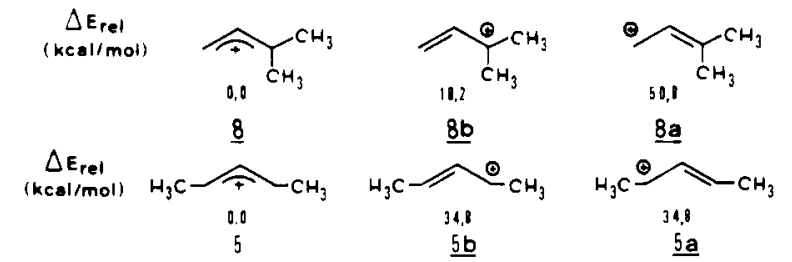

whereas, in symmetrically substituted allyl cations, the resonance energy is much larger $(34.8 \mathrm{kcal} / \mathrm{mol}$ for 5$)$. The total energy of allyl cations, however, does not depend on the magnitude of the resonance energy. Both 6 and 8 , the symmetrical and nonsymmetrical dimethylallyl cations, both with one endo-methyl, have almost identical energy (Table I). The same holds for 14 and 16 . The higher resonance energy of 5 , therefore, compensates for the energy difference between the secondary ion $\mathbf{5 a}$ and the tertiary ion $\mathbf{8 b}$. The actual energy, rather than the "resonance energy", is of primary concern to chemists.

\section{Conclusion}

Ab initio calculations even at the STO-3G minimal basis set level reproduce relative gas-phase stabilities of methylsubstituted allyl cations very well. In cases of contradictory experimental results, they may even serve to identify the correct value. The experimentally observed trends of solvolysis rates and rotational barriers are also reproduced by the calculations. The differences in solution are smaller than those indicated in the gas phase. This suggests the solvation of the more delocalized planar allyl forms to be less than that of the more highly localized transition states.

Acknowledgment. We are grateful to J. D. Dill, J. Chandrasekhar, J. B. Collins, and R. Krishnan for previous work in this field. We thank Professor M. Saunders for stimulating discussions and Professor D. H. Aue for communicating gasphase data to us previous to publication. Financial support by the Fonds der Chemischen Industrie and the Deutsche Forschungsgemeinschaft and computational assistance by the Rechenzentrum der Universität Erlangen-Nürnberg is gratefully acknowledged. The Erlangen version of the Gaussian 70 program benefited from routines written by H.-U. Wagner, D. Poppinger, and B. Schlegel, who kindly provided us with his FORCE program.

\section{References and Notes}

(1) Reviews: (a) R. H. DeWolfe and W. G. Young, Chem. Rev, 56, 753 (1956); (b) N. C. Deno in "Carbonium lons", Vol. II, G. A. Olah and P. V. R. Schleyer, Ed., Wiley-Interscience, New York, 1972, Chapter 18.

(2) D. H. Aue and M. T. Bowers, in "Gas-Phase lon Chemistry", M. T. Bowers, Ed., Academic Press, New York, 1979. Also see ref 26.

(3) S. D. Peyerimhoff and R. J. Buenker, J. Chem. Phys., 51, $2528(1969)$

(4) H. Kollmar and H. O. Smith, Theor. Chim. Acta, 20, 65 (1971)

(5) N. C. Baird, Tetrahedron, 28, 2355 (1972).

(6) M. Shanshal, J. Chem. Soc., Perkin Trans. 2, 335 (1972).

(7) L. Radom, P. C. Hariharan, J. A. Pople, and P. v. R. Schleyer, J. Am. Chem. Soc., 95, 6531(1973).

(8) B. K. Carpenter, J. Chem. Soc., Perkin Trans. 2, 1 (1974).

(9) (a) P. v. R. Schleyer, J. D. Dill, J. A. Pople, and W. J. Hehre, Tetrahedron, 33, 2497 (1977); (b) also see W. J. Hehre and J. A. Pople, J. Am. Chem. Soc., 97,6941 (1975).

(10) R. C. Bingham, M. J. S. Dewar, and D. H. Lo, J. Am. Chem. Soc., 97, 1294 (1975).

(11) N. L. Allinger and J. H. Siefert, J. Am. Chem. Soc., 97, 752 (1975).

(12) A. Sabljic, N. Trinajstic̀, J. V. Knop. J. Koller, and A. Azman, J. Mol. Struct., 33, 145 (1976)

(13) W. J. Hehre, R. F. Stewart, and J. A. Pople, J. Chem. Phys., 51, 2657 (1969).

(14) W. J. Hehre, W. A. Lathan, R. Ditchfield, M. D. Newton, and J. A. Pople, Gaussian 70, Program No. 236, Quantum Chemistry Program Exchange, Bloomington, Indiana

(15) Complete geometry optimization of 4, 6 and perpendicular 5 and 8 was carried out by using analytically calculated gradients: $H$. B. Schlegel, $S$. Wolfe, and F. Bernardi, J. Chem. Phys., 63, 3632 (1975).

(16) Slight distortions from planarity, which are energetically insignificant, cannot be excluded, however.

(17) G. A. Olah and R. J. Spear, J. Am. Chem. Soc., 97, 1539 (1975).

(18) ${ }^{13} \mathrm{C}$ NMR shitts of $\mathrm{C}-1$ and $\mathrm{C}-3.2 \delta 201.5,255.1: \mathrm{H}$. Mayr and $\mathrm{G}$. A. Olah, J. Am. Chem. Soc., 99, $510(1977) .5 \delta 232.3,8 \delta 175.0,274.3,11 \delta 206.0$, 251.8, $16 \delta$ 171.8, 273.2: G. A. Olah and H. Mayr, J. Am. Chem. Soc., 98, $7333(1976) ; 100,6544(1978) .13 \delta 232.9,17 \delta 234.9$ : G. A. Olah, P. R. Clifford, $Y$. Halpern, and R. G. Johanson, J. Am. Chem. Soc., 93, 4219 (1971).

(19) R. S. Mulliken, J. Chem. Phys., 23, 1833, 1841, 2338, 2343 (1955). 
(20) J. D. Dill, Ph.D. Thesis, Princeton University, 1975

(21) P. v. R. Schleyer, T. M. Su, M. Saunders, and J. C. Rosenfeld, J. Am. Chem Soc., 91,5174 (1969).

(22) J. M. Bollinger, J. M. Brinich, and G. A. Olah, J. Am. Chem. Soc., 92, 4025 (1970)

(23) W. J. Hehre in "Applications of Electronic Structure Theory", Vol. III, H. F. Schaefer III, Plenum Press. New York, 1977.

(24) Total STO-3G energies for ethane $(-78.30618$ au): W. A. Lathan, W. J. Hehre, and J. A. Pople, J. Am. Chem. Soc., 93, 808 (1971). Propane $(-116.88642$ au): L. Radom, W. A. Lathan, W. J. Hehre, and J. A. Pople, J. Am. Chem. Soc., 93, 5339 (1971).

(25) $\Delta H_{4}^{\circ}$ for $\mathrm{C}_{2} \mathrm{H}_{6}(-20.24 \mathrm{kcal} / \mathrm{mol})$ and $\mathrm{C}_{3} \mathrm{H}_{8}(-24.83 \mathrm{kcal} / \mathrm{mol})$ were taken from J. D. Cox and G. Pilcher, "Thermochemistry of Organic and Organometallic Compounds". Academic Press, New York, 1970

(26) F. P. Lossing and J. C. Traeger, Int. J. Mass. Spectrom. Ion Phys., 19, 9 (1976).

(27) (a) C. A. Vernon, J. Chem. Soc. 423 (1954); (b) H. C. Brown, C. G. Rao and M. Ravindranathan, J. Org. Chem., 43, $4939(1978)$.

(28) S. W. Benson, "Thermochemical Kinetics," 2nd ed., Wiley-Interscience, New York, 1976

(29) E. M. Arnett, C. Petro, and P. v. R. Schleyer, J. Am. Chem. Soc., 101, 522 (1979).

(30) Total STO-3G energy for ethyl cation ( -77.40806 au): ref 24a. Isopropyl cation $(-116.02765$ au $)$ : L. Radom, J. A. Pople, V. Buss, and P. V. R Schleyer, J. Am. Chem. Soc., 94, 311 (1972). tert-Butyl cation $(-154.63918$ au): ref 23

(31) $\Delta H_{4}^{\circ}$ for ethyl (219 kcal $/ \mathrm{mol}$ ), isopropyl ( $192 \mathrm{kcal} / \mathrm{mol}$ ), and tert-butyl cation (169 kcal/mol) were taken from F. P. Lossing and G. P. Semeluk, Can. J. Chem. 48, 955 (1970); we note that different values for these cations have been given recently; consider them not yet established, however: $D$. W. Berman, V. Anicich, and J. L. Beauchamp, J. Am. Chem. Soc., 101, 1239 (1979).

(32) Our work; in order to prevent the spontaneous 1,2 hydride shift during optimization of the perpendicular allyl cation, $\mathrm{C}^{1} \mathrm{C}^{2} \mathrm{C}^{3}$ and $\mathrm{HC}^{2} \mathrm{C}^{4}$ were kept at $120^{\circ} \mathrm{C}$.

(33) N. C. Deno, R. C. Haddon, and E. N. Novak, J. Am. Chem. Soc., 92, 6691 (1970).

(34) V. Buss, R. Gleiter, and P. V. R. Schleyer, J. Am. Chem. Soc., 93, 3927 (1971).

(35) $\Delta H_{4}^{\circ}(\mathrm{kcal} / \mathrm{mol})$ for $\mathrm{C}_{3} \mathrm{H}_{5}{ }^{+}$. (a) 226, F P Lossing Can $\mathrm{C}$ Chem 50, 3973 (1972); (b) 224.5, S. E. Buttrill, Jr., A. D. Williamson, and P. LeBreton, J. Chem. Phys., 62, 1586 (1975); (c) 227, R. Krässig, D. Reinke, and H. Baumgärtel, Ber. Bunsenges. Phys. Chem., 78, 425 (1974); (d) 225.5, F. A. Houle and J. L. Beauchamp, J. Am. Chem. Soc., 100, 3290 (1978).

(36) R. Krishnan and J. A. Pople, private communication to P. v. R. Schleyer: J. A. Pople, R. Seeger, and R. Krishnan, int. J. Quant. Chem. S., 11, 149 (1977).

(37) E. M. Arnett and C. Petro, J. Am. Chem. Soc., 100, 5402, 5408 (1978).

(38) L. Radom, J. A. Pople, and P. v. R. Schleyer, J. Am. Chem. Soc., 95, 8193 (1973).

(39) H. C. Brown, M. Ravindranathan, C. G. Rao, F. J. Chloupek, and M.-H. Rei, J. Org. Chem., 43, 3667 (1978).

(40) G. W. Wheland, "Resonance in Organic Chemistry," Wiley, New York, 1955, p. 75.

(41) See, however, discussion of Figure 5 which indicates hyperconjugative stabilization in the perpendicular cations. See also ref $7, p 6536$.

(42) A similar "inhibition of resonance" was observed in allylic nitrogen ylides: M. Saunders and E. H. Gold, J. Am. Chem. Soc., 88, 3376 (1966).

\title{
Isopropylation of Halobenzenes by $\mathrm{sec}-\mathrm{C}_{3} \mathrm{H}_{7}+$ Cations. Evidence for a Participation of the Substituent in a Gas-Phase Alkylation
}

\author{
Marina Attinà and Pierluigi Giacomello* \\ Contribution from the Università di Roma, 00100 Rome, Italy. \\ Received January 22, 1979
}

\begin{abstract}
Isopropylation of the halobenzenes $(\mathrm{PhF}, \mathrm{PhCl}$, and $\mathrm{PhBr})$ by isopropyl cations, generated in the diluted gaseous phase from the radiolysis of propane, leads to formation of the corresponding halocumenes. The regioselectivity of the substitution changes from apparent kinetic control, i.e., ortho $>80 \%$ at 760 Torr, to thermodynamic control i.e., meta, as the overall pressure is lowered to 20 Torr. The results of competitive alkylation experiments with toluene show the reactivity trend PhF $>\mathrm{PhCl} \simeq \mathrm{PhBr}$. Appreciable yields of anisole, increasing in the order $\mathrm{PhF}>\mathrm{PhCl} \simeq \mathrm{PhBr}$, are measured when the system is radiolyzed in the presence of $\mathrm{CH}_{3} \mathrm{OH}$. The formation of $\mathrm{PhOCH}_{3}$ is traced to the attack of methanol on the aromatic ring, activated toward nucleophilic displacement by a specific interaction of $s e c-\mathrm{C}_{3} \mathrm{H}_{7}+$ ions with the halogenated substrates. The same interaction helps also to explain the exceptionally high reactivity of the ring positions ortho to a n-donor substituent.
\end{abstract}

\section{Introduction}

Coordination effects ${ }^{1,2}$ have long been postulated to account for high ortho/para ratios in the liquid-phase alkylation of aromatic compounds bearing $n$-donor substituents, such as anisole and chlorobenzene. ${ }^{3}$ Recent studies by our group on gas-phase electrophilic aromatic substitution led to isolation of tert-butyl phenyl ether as the main product from the alkylation of phenol by unsolvated tert-butyl cations, providing direct evidence for predominant attack to the $\mathrm{OH}$ group, under conditions favoring kinetic control. ${ }^{4}$ Accordingly, in the case of anisole, ${ }^{5}$ where no neutral end product can directly arise from tert-butylmethylphenyloxonium ions, substantial amounts of o-tert-butylanisole have been recovered, confirming preferential reactivity of the charged electrophile toward the n-donor substituent. Analogous conclusions have been reached in the isopropylation of the same substrates by gaseous sec- $-\mathrm{C}_{3} \mathrm{H}_{7}+$ cations, ${ }^{6}$ which can undergo either proton transfer and condensation with both " $n$ " and " $\pi$ " nucleophilic sites of phenol and anisole.

The present work has been undertaken to collect further evidence on the specific interactions of carbenium ions and $\mathrm{n}$-donor substituents in the gas-phase electrophilic aromatic substitution, particularly in cases where proton transfer to the substituent is expected to be endothermic.

For this purpose, the alkylation of the halobenzenes ( $\mathrm{PhX}$, $\mathrm{X}=\mathrm{F}, \mathrm{Cl}, \mathrm{Br}$ ) by isopropyl cations from the radiolysis of propane has been studied in the diluted gaseous phase, where the absence of the counterion and of appreciable solvation effects brings into sharper focus the correlation between ionmolecule interactions and the formation of final neutral products.

According to a well-established technique, introduced by Ausloos and co-workers, ${ }^{7}$ high yields of sec-propyl ions can be obtained from the gas-phase radiolysis of propane. This method has already been exploited, 6,8 in combination with suitable analytical techniques, to study gas-phase electrophilic aromatic substitution by sec- $\mathrm{C}_{3} \mathrm{H}_{7}{ }^{+}$ions, and consists in carrying out the radiolysis of a system, prepared by mixing trace concentrations of the substrate(s) and of appropriate additives with a large excess of $\mathrm{C}_{3} \mathrm{H}_{8}$ and a few torr of oxygen, to cut off the radical component of the process. 